\title{
Analisis Daya Dukung Pondasi Dalam Proyek Pembangunan Gedung Jantung dan Paru-Paru Terpadu RSUD Kabupaten Sukoharjo
}

\author{
Susilo $^{1)}$ \\ 1) Fakultas Teknik, Program Studi Teknik Sipil, Universitas Veteran Bangun Nusantara, Sukoharjo, Jl. \\ Letjen Sudjono Humardhani, No.1, Jombor, Sukoharjo; Telp. 0271-593156. Email: su.susilo@ gmail.com
}

\begin{abstract}
Abstrak
Pondasi tiang atau disebut juga pondasi dalam dipergunakan untuk konstruksi beban berat ( high rise building ). Sebelum melaksanakan suatu pembangunan konstruksi yang pertama-tama dilaksanakan dan dikerjakan dilapangan adalah pekerjaan pondasi (struktur bawah). Pondasi merupakan suatu pekerjaan yang sangat penting dalam suatu pekerjaan teknik sipil, karena pondasi inilah yang memikul dan menahan suatu beban yang bekerja diatasnya yaitu beban konstruksi atas. Tujuan dari studi ini untuk menghitung daya dukung tiang pancang dari hasil sondir, Standart Penetration Test (SPT), dan berdasarkan parameter kuat geser tanah, membandingkan hasil daya dukung tiang pancang dan menghitung penurunan yang terjadi pada tiang pancang. Metodologi pengumpulan data dilakukan dengan cara melakukan observasi, pengambilan data dari pihak proyek serta melakukan studi keperpustakaan. Pada perhitungan daya dukung tiang pancang dilakukan dengan metode Meyerhof dan berdasarkan parameter kuat geser tanah. Berdasarkan data sondir, SPT, parameter kuat geser tanah yang diperoleh dan dihitung . Dari analisis didapat berbagai Alternatif yakni diameter 0,8 m, 0,7 m, 0,6 m, diambil alternatif ke-2 diameter 0,7 $\mathrm{m}$ dengan metode Meyerhoff Kapasitas daya dukung pondasi tiang ditentukan oleh kemampuan material tiang untuk menahan beban struktural. Berdasarkan hasil analisis diperoleh tegangan yang terjadi pada tiang sebesar 325,78 Ton > 310 Ton, sehingga pondasi aman digunakan. Analisis tiang kapasitas dukung penurunan tiang pancang metode Meyerhoff diameter 0,8 m sebesar 0,00197 m, 0,7 m sebesar 0,00257 m, 0,6 m sebesar 0,00349 m.
\end{abstract}

Kata kunci: pondasi tiang pancang, metode meyerhoff.

\begin{abstract}
Pile foundation or also called deep foundation is used for heavy load construction (high rise building). Before carrying out construction, the first thing to be carried out and carried out in the field is the foundation work (lower structure). The foundation is a work that is very important in civil engineering work, because it is this foundation that carries and holds a load that works on it, namely the upper construction load. The purpose of this study is to calculate the bearing capacity of piles from the results of the sondir, Standard Penetration Test (SPT), and based on soil shear strength parameters, to compare the results of the bearing capacity of piles and calculate the settlement that occurs in piles. The data collection methodology is carried out by making observations, collecting data from the project, and conducting library studies. The calculation of the bearing capacity of piles is carried out using the Meyerhof method and based on soil shear strength parameters. Based on sondir data, SPT, soil shear strength parameters were obtained and calculated. From the analysis obtained various alternatives, namely the diameter of $0.8 \mathrm{~m}, 0.7 \mathrm{~m}, 0.6 \mathrm{~m}$, taken the second alternative with the diameter of $0.7 \mathrm{~m}$ with the Meyerhoff method. The carrying capacity of the pile foundation is determined by the ability of the pile material to withstand structural loads. Based on the results of the analysis, it is found that the stress that occurs on the pile is 325.78 tons $>310$ tons so that the foundation is safe to use. Analysis of pile bearing capacity for lowering of the Meyerhoff pile method with a diameter of $0.8 \mathrm{~m}$ is $0.00197 \mathrm{~m}, 0.7 \mathrm{~m}$ is $0.00257 \mathrm{~m}, 0.6 \mathrm{~m}$ is $0.00349 \mathrm{~m}$.
\end{abstract}

Keywords: pile foundation, Meyerhoff method.

\section{PENDAHULUAN}

Rumah sakit merupakan sarana yang memberikan pelayanan kesehatan kepada masyarakat dan memiliki peran yang sangat strategis dalam mempercepat peningkatan derajat kesehatan masyarakat.

Menurut Vitruvius di dalam bukunya $D e$ Architetura, Bangunan yang baik haruslah memiliki keindahan atau estetika (venustas), kekutan (firmitas), dan kegunaan atau fungsi (utilitas). Sehingga bangunan tidak hanya sekedar berdiri saja, melainkan harus mempunyai tiga unsur yang disebutkan di atas (Sumoharjo,2009).

RSUD Kabupaten Sukoharjo adalah rumah sakit milik Pemerintah Kabupaten Sukoharjo dan merupakan rumah sakit kelas B yang 
menyediakan jasa pelayanan kesehatan bagi masyarakat Sukoharjo secara khusus dan mencakup masyarakat seluruh Indonesia secara luas. Dengan semakin banyaknya kasus pasien penderita jantung dan paru-paru, maka RSUD Kabupaten Sukoharjo untuk mencukupi akan kebutuhan fasilitas kesehatan tersebut salah satunya dengan membangun Gedung Jantung dan Paru-Paru Terpadu. Gedung Jantung dan Paru-Paru Terpadu pada umumnya terdiri dari ruangan-ruangan yang memiliki alur sirkulasi pelayanan sesuai dengan standar pelayanan kesehatan.

Seiring dengan kemajuan dan peningkatan pembangunan pada RSUD Kabupaten Sukoharjo yang berdampak pada semakin berkurangnya lahan kosong, maka untuk mencukupi kebutuhan ruang tersebut pembangunan Gedung dan Jantung Paru-Paru Terpadu tersebut di rencanakan secara vertical keatas.Sama halnya dengan bangunan sipil lainnya gedung rumah sakit ini terbagi atas dua bagian yakni struktur atas dan struktur bawah. Dimana kestabilan suatu struktur tidak hanya ditentukan oleh struktur atas yang secara langsung memikul gaya-gaya yang bekerja pada struktur tersebut, tetapi kestabilan struktur bawah dalam hal ini pondasi memegang peranan yang tidak kalah penting dalam menjaga kestabilan struktur tersebut (Minmahddun, 2014).

Bowles (1988, dalam Surjandari, 2008) mengemukakan pondasi dalam digunakan jika lapisan tanah keras atau batuan berada pada posisi yang dalam. Penggunaan pondasi dalam sebagai pondasi bangunan apabila tanah yang berada di bawah dasar bangunan tidak mempunyai daya dukung (bearing capacity) yang cukup untuk memikul berat bangunan dan beban yang bekerja padanya (Sardjono, 1988). Atau apabila tanah yang mempunyai daya dukung yang cukup untuk memikul berat bangunan dan seluruh beban yang bekerja berada pada lapisan yang sangat dalam dari permukaan tanah kedalaman > 8m (Bowles, 1997). Jenis pondasi dalam yang digunakan pada Proyek Pembangunan Gedung Jantung dan Paru-Paru Terpadu RSUD Kabupaten Sukoharjo adalah pondasi tiang pancang. Dalam perencanaan pondasi tiang pancang, permasalahan penting yang harus diperhatikan adalah besar daya dukung tanah yang mampu memikul beban kerja yang bekerja pada pondasi, dimana daya dukung yang dimiliki harus lebih besar dari beban yang akan dipikul oleh pondasi tersebut. Selain daya dukung yang memadai hal lain yang harus diperhatikan dalam perancanaan pondasi adalah mengenai penurunan pondasi tersebut, sebab pondasi tetap akan mengalami penurunan akibat beban yang dipikulnya sehingga menyebabkan pemampatan pada tanah dibawah pondasi tersebut.

\section{METODE}

\section{Metode penelitian}

Adapun data yang dipergunankan dalam analisis data pada tugas akhir ini adalah sebagai berikut:

1. Data laporan hasil uji Cone Penetration Test ( CPT ) pada proyek pembangunan gedung rumah sakit jantung dan paru-paru terpadu RSUD Sukoharjo.

2. Data laporan hasil uji Laboratorium Mekanika Tanah Laboratorium Mekanika pada proyek pembangunan gedung rumah sakit jantung dan paru-paru terpadu RSUD Sukoharjo.

Data tanah yang digunakan pada tugas akhir ini adalah data yang bersumber dari penyelidikan tanah dengan Hand Boring, Cone Penetration Test (CPT) dan data Uji Penetrasi Statis (Sondir).

Pembebanan pada pilecap gedung rumah sakit dianalisis dengan aplikasi SAP 2000 yang diperoleh dari data perencana, mengacu pada peraturan pembebanan Indonesia dengan beban yang bekerja yakni beban vertikal dan beban horizontal. Semua jenis-jenis pembebanan dimodelkan dengan bantuan program SAP 2000. Beban-beban tersebut di kombinasikan untuk mendapatkan beban terfaktor maksimum. Setelah data-data dan pembebanan diketahui, selanjutnya adalah menganalisis Daya dukung dan penurunan pondasi tiang pancang dengan menggunakan cara manual.

- Metode Meyerhoff

Meyerhoff (1956) menganjurkan formula daya dukung untuk tiang pancang sebagai berikut :

$\mathrm{Qu}=40 \mathrm{Nb} . \mathrm{Ap}+0.2 \mathrm{~N}$. As

dengan:

$\mathrm{Qu}=$ daya dukung ultimit pondasi tiang pancang (ton)

$\mathrm{Nb}=$ harga N-SPT pada elevasi dasar tiang

$\mathrm{Ap}=$ luas penampang dasar tiang (m2)

As $=$ luas selimut tiang $(\mathrm{m} 2)$

$\mathrm{N}=$ harga $\mathrm{N}-\mathrm{SPT}$ rata rata 
Untuk tiang dengan desakan tanah yang kecil seperti tiang bor dan tiang baja $\mathrm{H}$,

maka daya dukung selimut hanya diambil separuh dari formula diatas, sehingga menjadi:

Qult $=40 \mathrm{Nb} . \mathrm{Ap}+0.1 \mathrm{~N} . \mathrm{As}$

\section{HASIL DAN PEMBAHASAN}

\section{Perhitungan Kuat Pondasi Dengan Metode Meyerhoff dengan Data Sondir}

1. Tiang Pancang Diameter $=0,8 \quad \mathrm{~m}$ a. Kapasitas Dukung Ujung Tiang $\mathrm{qc}=200 \mathrm{Kg} / \mathrm{cm} 2$

$=19620 \mathrm{KN} / \mathrm{m} 2$

$\mathrm{Ap}=0.25 \quad 3,14 \quad \mathrm{D} 2$

$=0,25 \quad 3,14 \quad 0,64$

$=0,5024 \mathrm{~m} 2$

$\mathrm{Qp}=\mathrm{qc} \cdot \mathrm{Ap}$

$=196200,5024$

$=9857,09 \mathrm{KN}$

b. Kapasitas Dukung Tiang Selimut $\mathrm{JHL}=1020 \mathrm{Kg} / \mathrm{cm} 2$

$=100062 \mathrm{KN} / \mathrm{m} 2$

$\mathrm{K}=3,14 \times \mathrm{D}$

$=3,14 \times 0,8$

$=2,512 \mathrm{~m}$

$\mathrm{Qs}=\mathrm{JHL} \times \mathrm{K}$

$=100062 \times 2,512$

$=2513,56 \quad \mathrm{KN}$

C. Kapasitas Dukung Ultimit Tiang

$\mathrm{Qu}=\mathrm{Qp}+\mathrm{Qs}$

$=9857,09 \quad \mathrm{KN}+2513,56$

d. Kapasitas Dukung Tiang

Qijin $=(\mathrm{Qu} / \mathrm{Sf})-\mathrm{Wp}$

$$
\begin{aligned}
& =12370,6 / 3-1 / 4 \cdot 3,14 . \quad 0,64 \\
& =4122,33 \mathrm{KN} \\
& =412,233 \text { Ton }
\end{aligned}
$$

Dapat disimpulkan bahwa:

$$
\begin{aligned}
& 412,233>310 \\
& \text { Pondasi OK }
\end{aligned}
$$

\section{Efisiensi Tiang $=100 \%$}

2. Tiang Pancang Diameter $=0,7 \quad \mathrm{~m}$ a. Kapasitas Dukung Ujung Tiang

$$
\begin{aligned}
& \mathrm{qc}=200 \mathrm{Kg} / \mathrm{cm} 2 \\
& =19620 \mathrm{KN} / \mathrm{m} 2 \\
& \mathrm{Ap}=0.25 \quad 3,14 \quad \mathrm{D} 2 \\
& =0,25 \quad 3,14 \quad 0,49 \\
& =0,38465 \quad \mathrm{~m} 2 \\
& \mathrm{Qp}=\mathrm{qc} \cdot \mathrm{Ap} \\
& =196200,3847 \\
& =7546,83 \quad \mathrm{KN}
\end{aligned}
$$

b. Kapasitas Dukung Tiang Selimut $\mathrm{JHL}=1020 \mathrm{Kg} / \mathrm{cm} 2$

$=100062 \mathrm{KN} / \mathrm{m} 2$

$\mathrm{K}=3,14 \times \mathrm{D}$

$=3,14 \times 0,7$

$=2,198 \mathrm{~m}$

Qs $=$ JHL $\times \mathrm{K}$

$=100062 \times 2,198$

$=2199,36 \quad \mathrm{KN}$

C. Kapasitas Dukung Ultimit Tiang

$\mathrm{Qu}=\mathrm{Qp}+\mathrm{Qs}$

$$
\begin{aligned}
& =7546,83+2199,36 \\
& =9746,2 \quad \mathrm{KN}
\end{aligned}
$$

d. Kapasitas Dukung Tiang

Qijin $=(\mathrm{Qu} / \mathrm{Sf})-\mathrm{Wp}$

$$
\begin{aligned}
& =9746,2 / 3-1 / 4.3,14.0,49 \\
& =3247,8 \mathrm{KN} \\
& =324,78 \mathrm{Ton}
\end{aligned}
$$

Dapat disimpulkan bahwa:

$$
324,78<412,233 \text { Ton }
$$

Efisiensi Daya Dukung Tiang $=79 \%$

3. Tiang Pancang Diameter $=0,6 \mathrm{~m}$ a. Kapasitas Dukung Ujung Tiang $\mathrm{qc}=200 \mathrm{Kg} / \mathrm{cm} 2$

$$
=19620 \mathrm{KN} / \mathrm{m} 2
$$

$\mathrm{Ap}=0.25 \quad 3,14 \quad \mathrm{D} 2$

$=0,25 \quad 3,14 \quad 0,36$

$=0,2826 \quad \mathrm{~m} 2$

$\mathrm{Qp}=\mathrm{qc} \cdot \mathrm{Ap}$

$=196200,2826$

$=5544,61 \mathrm{KN}$

b. Kapasitas Dukung Tiang Selimut $\mathrm{JHL}=1020 \mathrm{Kg} / \mathrm{cm} 2$

$$
=100062 \mathrm{KN} / \mathrm{m} 2
$$

$\mathrm{K}=3,14 \times \mathrm{D}$

$=3,14 \times 0,6$

$=1,884 \mathrm{~m}$

Qs $=$ JHL $\times \mathrm{K}$

$=100062 \times 1,884$

$=1885,17 \mathrm{KN}$

C. Kapasitas Dukung Ultimit Tiang

$\mathrm{Qu}=\mathrm{Qp}+\mathrm{Qs}$

$$
=5544,61+1885,17
$$$$
=7429,78 \mathrm{KN}
$$

d. Kapasitas Dukung Tiang

Qijin $=(\mathrm{Qu} / \mathrm{Sf})-\mathrm{Wp}$

$$
\begin{aligned}
& =7429,78 / 3-1 / 4 \cdot 3,14 . \quad 0,36 \\
& =2475,91 \mathrm{KN} \\
& =247,591 \mathrm{Ton}
\end{aligned}
$$

Dapat disipulkan bahwa:

$$
247,591<412,233 \text { Ton }
$$

Efisiensi Daya Dukung Tiang $\quad=60 \%$ 


\section{Perhitungan Penurunan Tiang Pancang Dengan Metode Meyerhoff dengan Data Sondir}

1 Penurunan Tiang Pancang $\quad 0,8 \quad \mathrm{~m}$ Metode Meyerhoff

$$
\begin{aligned}
\mathrm{D} & =0,8 \\
\mathrm{Q} & =310 \mathrm{Ton} \\
\mathrm{L} & =8,2 \mathrm{~m} \\
\mathrm{AP} & =1 / 4.3,14 \quad 0,8 \quad 2 \\
& =0,5024 \mathrm{~m}^{2} \\
\mathrm{EP} & =4700 \times \sqrt{f^{\prime} c} \\
& =4700 \times \sqrt{30} \\
& =25743 \mathrm{Ton} \\
\mathrm{S} & =\mathrm{D} / 100+\text { Q.L/Ap.Ep } \\
& =0,008+2542 / 12933,263 \\
& =0,00197 \quad \mathrm{~m}
\end{aligned}
$$

2 Penurunan Tiang Pancang $\quad 0,7 \quad \mathrm{~m}$ Metode Meyerhoff

$$
\begin{aligned}
\mathrm{D} & =0,7 \\
\mathrm{Q} & =310 \mathrm{Ton} \\
\mathrm{L} & =8,2 \mathrm{~m} \\
\mathrm{AP} & =1 / 4.3,14 \quad 0,7 \quad 2 \\
& =0,38465 \quad \mathrm{~m}^{2} \\
\mathrm{EP} & =4700 \times \sqrt{f^{\prime} c} \\
& =4700 \times \sqrt{30} \\
& =25743 \text { Ton } \\
\mathrm{S} & =\mathrm{D} / 100+\text { Q.L/Ap.Ep } \\
& =0,007+2542 / 9902,0296 \\
& =0,00257 \quad \mathrm{~m}
\end{aligned}
$$

3 Penurunan Tiang Pancang $\quad 0,6 \quad \mathrm{~m}$ Metode Meyerhoff

$$
\begin{aligned}
\mathrm{D} & =0,6 \\
\mathrm{Q} & =310 \mathrm{Ton} \\
\mathrm{L} & =8,2 \mathrm{~m} \\
\mathrm{AP} & =1 / 4.3,14 \quad 0,6 \quad 2 \\
& =0,2826 \quad \mathrm{~m}^{2} \\
\mathrm{EP} & =4700 \times \sqrt{f^{\prime} c} \\
& =4700 \times \sqrt{30} \\
& =25743 \mathrm{Ton} \\
\mathrm{S} & =\mathrm{D} / 100+\text { Q.L/Ap.Ep } \\
& =0,006+2542 / 7274,9606 \\
& =0,00349 \quad \mathrm{~m}
\end{aligned}
$$

\section{Hasil Analisis Pondasi Tiang Pancang}

Perhitungan kapasitas daya dukung pondasi tiang pancang dibandingkan antara diameter 0,8 $\mathrm{m}, 0,7 \mathrm{~m}, 0,6 \mathrm{~m}$, dengan pondasi tiang Pancang (pondasi yang terpasang pada proyek dengan diameter $0,8 \mathrm{~m}$ ) agar dapat diambil kesimpulan dari hasil analisis kapasitas daya dukung pondasi tiang. Analisis kapasitas dukung pondasi tiang pancang menggunakan data SPT dengan diameter tiang sebesar $0,8 \mathrm{~m}, 0,7 \mathrm{~m}, 0,6$ $\mathrm{m}$. Kapasitas dukung pondasi diperoleh dari daya dukung ujung dan tahanan gesek selimut tiang.

Tabel 1. Rekapitulasi Analisis Kapasitas Dukung Pondasi Taing Pancang Pondasi Taing Pancang (Ton ) Metode Meyerhoff

\begin{tabular}{cccc}
\multicolumn{4}{c}{ Metode Meyerhoff } \\
\hline D & $0,8 \mathrm{~m}$ & $0,7 \mathrm{~m}$ & $0,6 \mathrm{~m}$ \\
\hline Qp (Ton) & 985,709 & 754,683 & 554,461 \\
\hline Qs (Ton) & 251,356 & 219,936 & 188,517 \\
\hline Qu (Ton) & 1237,06 & 974,62 & 742,978 \\
\hline Qall (Ton) & 412,233 & 324,78 & 247,591 \\
\hline
\end{tabular}

\section{Metode Meyerhoff}

2000

Qp (Ton) Qs (Ton) Qu (Ton) Qall (Ton)

$\square 0,8 \mathrm{~m} \quad 0,7 \mathrm{~m} \quad 0,6 \mathrm{~m}$

Gambar 1. Perbandingan Kapasitas Dukung Tiang Pancang

\section{Hasil Penurunan Tiang Pancang}

Besarnya penurunan pondasi tiang tergantung pada nilai beban-beban yang bekerja selain itu dipengaruhi juga oleh diameter tiang, jumlah tiang, formasi kelompok tiang, jenis material tiang, dan jenis material tanah. Penurunan pondasi kelompok tiang pada umunya lebih besar dari penurunan pada tiang tunggal. Hal ini dikarenakan adanya pengaruh tegangan pada daerah cakupan yang lebih luas serta lebih dalam.

Tabel 2. Rekapitulasi Hasil Penurunan Tiang Pancang

\begin{tabular}{cc}
\multicolumn{2}{c}{ Penurunan Pondasi Taing Pancang $(\mathrm{m})$} \\
\hline $\mathrm{D}(\mathrm{m})$ & Metode Meyerhoff \\
\hline $0,8 \mathrm{~m}$ & 0,00197 \\
\hline $0,7 \mathrm{~m}$ & 0,00257 \\
\hline $0,6 \mathrm{~m}$ & 0,00349 \\
\hline
\end{tabular}




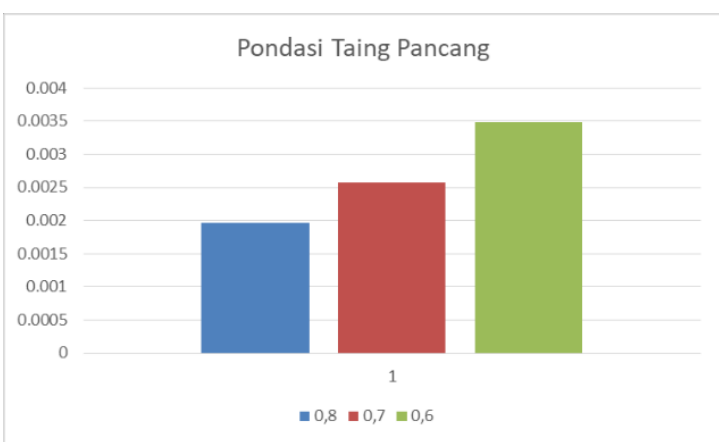

Gambar 2. Perbandingan Penurunan Tiang Pancang

\section{Hasil Analisis Kekuatan Tiang Pancang}

Dengan berbagai alternatif yakni diameter 0,8 $\mathrm{m}, 0,7 \mathrm{~m}, 0,6 \mathrm{~m}$, diambil alternatif ke-2 diameter 0,7 $\mathrm{m}$ dengan metode Meyerhoff.

Kapasitas dukung pondasi tiang ditentukan oleh kemampuan material tiang untuk menahan beban struktural. Berdasarkan hasil analisis diperoleh tegangan yang terjadi pada tiang sebesar 324,78 Ton < 412,233 Ton dengan efisiensi keamanan tiang yaitu $79 \%$ sehingga pondasi masih aman dan memenuhi syarat untuk digunakan.

\section{SIMPULAN}

Berdasarkan analisis kapasitas daya dukung pondasi tiang didapatkan beberapa kesimpulan dengan berbagai Kapasitas daya dukung 0,8 m, $0,7 \mathrm{~m}, 0,6 \mathrm{~m}$, diambil alternatif ke-2 diameter $0,7 \mathrm{~m}$ dengan metode Meyerhoff Kapasitas dukung pondasi tiang ditentukan oleh kemampuan material tiang untuk menahan beban struktural. Berdasarkan hasil analisis diperoleh tegangan yang terjadi pada tiang sebesar 324,78 Ton $<$ 412,233 Ton dengan efisiensi keamanan tiang yaitu $79 \%$ sehingga pondasi masih aman dan memenuhi syarat untuk digunakan. Penurunan tiang pancang dengan metode Meyerhoff diameter $0,8 \mathrm{~m}$ sebesar $0,00197 \mathrm{~m}, 0,7 \mathrm{~m}$ sebesar $0,00257 \mathrm{~m}$, $0,6 \mathrm{~m}$ sebesar $0,00349 \mathrm{~m}$.

\section{DAFTAR PUSTAKA}

Abbas, Jasim M. 2008. Single Pile Simulation and Analysis Subjected to Lateral Load. Journal of Ejdge, Vol. 13,Bund.E.

Brinkgreve, R.J.B., 2002, Reference_Manual_V.8, Manual Plaxis, A. A Balkema Publisher.

Bowles, J.E. 1988. Foundation Analysis and Design, McGraw-Hill Kogakusha, Ltd, Tokyo, Japan.

Day, R.W. 2010. Foundation Engineering Handbook., McGraw-Hill, New York, USA.

Departemen Pekerjaan Umum, 1983, Peraturan Pembebanan Indonesia untuk Gedung, PPI1983, Jakarta.

Hadiyatmo, H.C. 2010. Analisis dan Desain Foundasi Bagian II. Gadjah Mada University press, Yogyakarta.

Minmahddun, Anafi. 2014. Analisis Daya Dukung Pondasi Tiang Pancang pada Rencana Pmebangunan Dermaga Ereke. Skripsi. Teknik Sipil UHO. Kendari.

Redana, I.W. 2009. Teknik Pondasi. Udayana University press, Denpasar.

Sardjono H.S., 1988. Pondasi Tiang Pancang Jilid I, Sinar Wijaya, Surabaya. 